\title{
Land use transitions and their effects on water environment in Huang-Huai-Hai Plain, China
}

\author{
Yongqiang Liu ${ }^{\mathrm{a}, \mathrm{b}}$, Hualou Long ${ }^{\mathrm{a}, *}$, Tingting $\mathrm{Li}^{\mathrm{a}, \mathrm{b}}$, Shuangshuang $\mathrm{Tu}^{\mathrm{a}, \mathrm{b}}$ \\ a Institute of Geographic Sciences and Natural Resources Research, Chinese Academy of Sciences, Beijing 100101, China \\ ${ }^{\mathrm{b}}$ University of Chinese Academy of Sciences, Beijing 100049, China
}

\section{A R T I C L E I N F O}

\section{Article history:}

Received 17 February 2015

Received in revised form 14 April 2015

Accepted 23 April 2015

\section{Keywords:}

Land use transition

Environmental effect

Water environmental quality

Spatial regression analysis

Management policy

Urban-rural transformation development

China

\begin{abstract}
A B S T R A C T
This paper analyzes the spatio-temporal dynamic patterns of land use in Huang-Huai-Hai Plain, one of the China's most important grain production bases experiencing rapid urban-rural transformation development, using high-resolution Landsat TM (Thematic Mapper) data and series data of water environmental quality monitoring in 2000 and 2010, and related socio-economic data from government departments. After assessing the change of water environmental quality of Huang-Huai-Hai Plain during 2000-2010, three spatial econometric regression models including Spatial Lag Model(SLM), Spatial Error Model(SEM) and ordinary least squares (OLS) are used to explore the correlationships between land use transitions and water environmental changes. The outcomes indicated that, during the research period, land use pattern changes in the study area were characterized by the loss of large quantities of farmland and the increase of construction land and water body. On the whole, the water environment in the study area was obviously improved, but there also existed partial deterioration as evidenced by the increase of monitoring sections with water environmental quality below Class V. In general, the increases of grassland, forested land and water body have positive effects on water environmental quality while farmland and construction land have negative effects on that. The authors argue that construction land use and farmland use have almost equal negative effects on water environmental quality, and managing agricultural non-point source pollution is pivotal to improve local water environmental quality. Finally, some of the major implications for managing the land and water resources in the plain areas of China as well as other developing countries undergoing rapid urban-rural transformation development are discussed in the aspects of ecological farming practices, rural construction land management, land use planning and urban planning.
\end{abstract}

(c) 2015 Elsevier Ltd. All rights reserved.

\section{Introduction}

With the acceleration of urbanization and subsequent increase of human activities, significant changes occurred in the aspects of regional land use and their patterns at different scale, leading to tremendous land use transitions (Andersson et al., 2011; Chen et al., 2014; Lambin and Meyfroidt, 2010; Liu et al., 2010; Long, 2014a; Long et al., 2009; Robinson and Carson, 2013; Tan et al., 2011). The land use types of the river basin have been gradually transformed to agricultural or urban land from natural vegetation due to human activities, which caused the degradation of water environmental quality finally (Amiri and Nakane, 2009; Gao et al., 2004; Johnson et al., 1997; Mou et al., 2004; Uuemaa et al., 2007). Under

\footnotetext{
* Corresponding author. Tel.: +86 1064888169

E-mail address: longhl@igsnrr.ac.cn (H. Long).
}

the condition of point-source pollution has been effectively controlled, non-point source pollution from agricultural land use and private rural land has become one of the most important issues for the management of freshwater worldwide because of its extensive and uncertainty (Duncan, 2014; Short, 2013; Zhang et al., 2011). Temporal and spatial changes of land use are regarded as one of the main factors of non-point source pollution, not only because it affects the surface runoff, evaporation, infiltration of hydrological processes (Chen et al., 2003; Fu et al., 2005), but also influences the substance form and its transportation, biogeochemical cycle and a series of other ecological processes, thereby changing the number of pollutants flowed into rivers and lakes which causes an important impact on water environmental quality finally (Li et al., 2013; Mehaffey et al., 2005).

The plain areas in China have made a great contribution in ensuring China's food security and have been regarded as the most important grain production bases. However, due to lacking of 
effective land use planning and management, these plain areas paid a heavy price for this, evidenced by having brought about severe environmental problems. For example, there are about more than 5500 million tons of fertilizer and 170 tons of pesticide per year used in the plain areas (NBSC, 2012), but quite a few has not been absorbed by crops, which flowed into surface waters ultimately, causing serious water pollution and threatening the sustainable socio-economic development (Jia et al., 2010; Zhang et al., 2014; Zhang and Kong, 2014).

Land use transitions and their environmental effects have become the focus of land change science (Cai, 2011, 2013; Li, 2008, 2009; Li et al., 2010a,b; Long, 2014b; Long et al., 2014; Turner et al., 2007). Currently, some countermeasures such as water environmental quality monitoring, evaluation and point-source pollution control are not sufficient enough to handle a series of problems concerning water environmental quality deterioration and aquatic ecosystem degradation in the process of China's rapid urbanization. As for water environment management, while there are numerous studies focusing on the sensitivity of water environmental quality (Liu et al., 2014a; Versace and Ierodiaconou, 2008; Zampella et al., 2007), scale effect and distance effect (Basnyat et al., 1999; King et al., 2005; Li et al., 2010a,b; Liu et al., 2014b) due to the land use/cover change, the quantitative studies of the correlation between land use transitions and water environmental quality change have found much less attention.

The aims of this paper are: (1) to examine the spatio-temporal dynamic patterns of land use in Huang-Huai-Hai Plain experiencing rapid urban-rural transformation development, using high-resolution Landsat TM (Thematic Mapper) data and series data of water environmental quality monitoring in 2000 and 2010, and related socio-economic data from government departments; (2) to assess the change of water environmental quality of HuangHuai-Hai Plain during 2000-2010, using the mathematical statistics and analyze its spatio-temporal variations; (3) to explore the correlationships between land use transitions and water environmental changes based on spatial regression analysis; and (4) to discuss some of the major implications for managing the land and water resources in the plain areas of China as well as other developing countries undergoing rapid urban-rural transformation development.

\section{Study area}

Huang-Huai-Hai Plain, the study area, is located in the south of the Yan Mountain, the north of the Dabie Mountains, the east of Taihang Mountain and Funiu Mountain, and the west of Bohai and the Yellow Sea, including the areas of five provinces and two municipalities, i.e., the whole Shandong, most of the Beijing, Tianjin, Hebei and Henan, and north part of Anhui and Jiangsu, and it covers about 400 thousand $\mathrm{km}^{2}$ (Fig. 1). Huang-Huai-Hai Plain has a population of 210 million or more in 2009, and it is a representative of China's plains, its land area and population account for $31.7 \%$ and $52.6 \%$, respectively, of the total plain areas in China (Li et al., 2012). The farmland of Huang-Huai-Hai Plain accounts for about one-sixth of China's total and ranks the first in terms of land reclamation rate, with 50 million ha sowing area, 33\% that of the whole country, and producing $35-40 \%$ and $60-80 \%$ of China's wheat and corn, respectively, which has played an important role in ensuring the national food security (Kong et al., 2014; Li et al., 2012). In Huang-Huai-Hai Plain, there are a large number of rivers and lakes, which belong to four major river basins, i.e., Yellow River Basin, Huaihe River Basin, Haihe River Basin and Coastal Jiaodong Basin. The total amount of water resources is only about 70 billion $\mathrm{m}^{3}$ and accounts for only one-eighth of national average farmland water consumption per mu ( $1 \mathrm{mu}=1 / 15 \mathrm{ha}$ ) (Zhang and Kong, 2014). Huang-Huai-Hai Plain is characterized by water shortages and diffusing pollution from agricultural sources (Kong et al., 2014; Qiu, 2010; Yu et al., 2011).

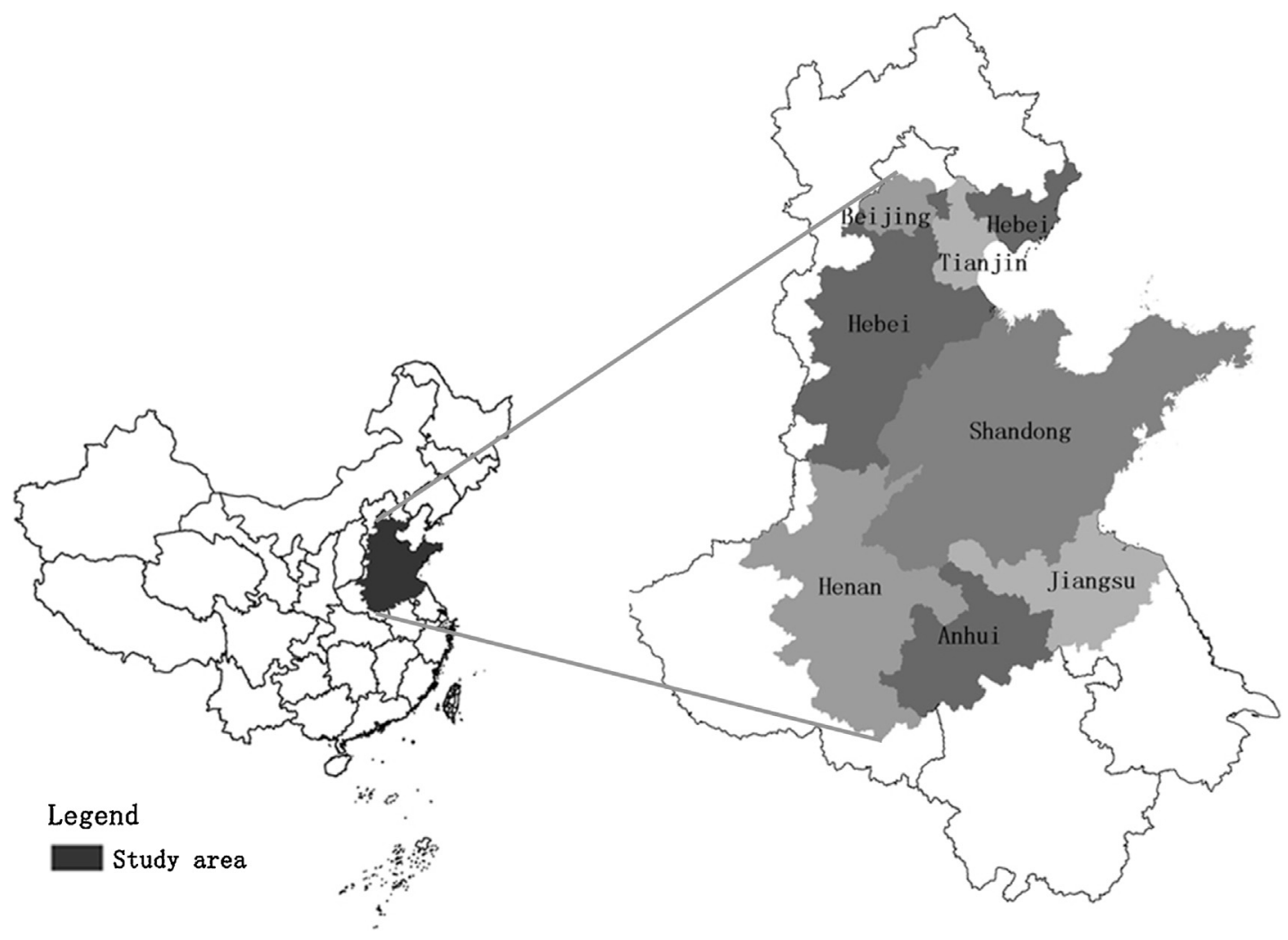

Fig. 1. Location of the study area. 

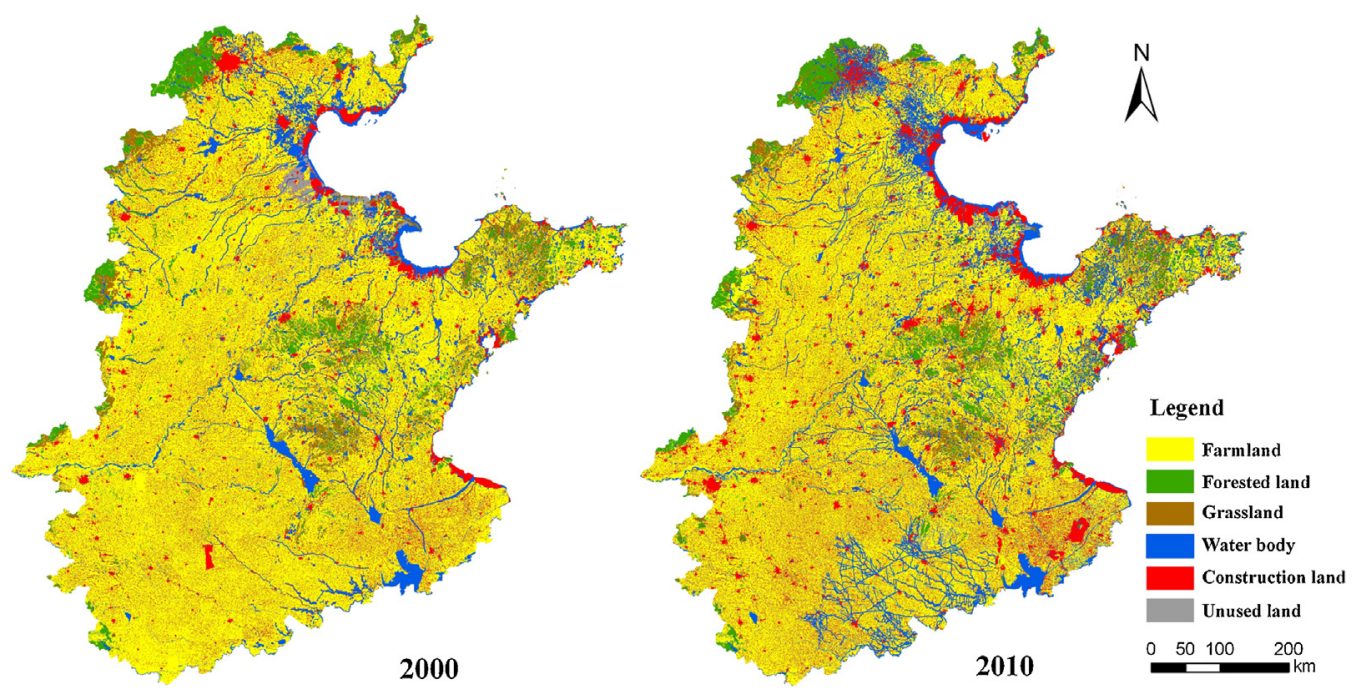

Fig. 2. Land use of Huang-Huai-Hai Plain in 2000 and 2010.

\section{Materials and methods}

\subsection{Data source and processing}

The vector data of land-use and land-cover (LULC) change was obtained through detection analysis of historical Landsat TM (Thematic Mapper) satellite images in 2000 and 2010 from the China National Environmental Monitoring Center. An efficient classification system was drafted and an effective research team was organized to work on remote sensed data through human-machine interactive interpretation to guarantee classification consistency and accuracy. After geometrical image correction and geo-referencing, the average location errors were estimated at less than $50 \mathrm{~m}$ (about two pixels). An out-door survey and random sample check verified that the average interpretation accuracy for LULC was 91.2\% (Liu et al., 2014c). Based on these Landsat TM data, two land use maps in 2000 and 2010 were classified into six LULC types: farmland, water body, forested land, grassland, unused land, and construction land mainly for industry, mining and transportation as well as urban and rural settlements (Fig. 2). Then, we measured the variations among the 6 different LULC types using ESRI's ArcGIS spatial analyst module (Long et al., 2007). There are 187 water monitoring sections in Huang-Huai-Hai Plain (Fig. 3). The series data of water environmental quality monitoring from 2000 to 2010 are also supplied by the China National Environmental Monitoring Center. Water environmental quality is divided into six classes, i.e., Classes I-V, and below Class V (SEPA, 2002). Class I refers to the water in the source and national nature reserve. Class II refers to the water in the first-grade protection zone of centralized drinking water source, rare aquatic habitats, spawning ground and little fish feeding grounds et al. Class III refers to the water in the second-grade protection zone of centralized drinking water source, fish and shrimp overwintering ground, migration route, aquaculture area and swimming area et al. Class IV refers to the industrial water and recreational water et al. Class $V$ refers to agricultural water and landscape water. Below Class $V$ refers to the water inferior to Class V. In addition, some socio-economic data such as the fertilizer and pesticide utilization are collected from Chinese Statistical Yearbook and Chinese rural Statistical Yearbook during 2000-2010.

\subsection{Methods}

When the land use types of a river basin mostly consist of residential land, agricultural land and industrial land, water pollutants

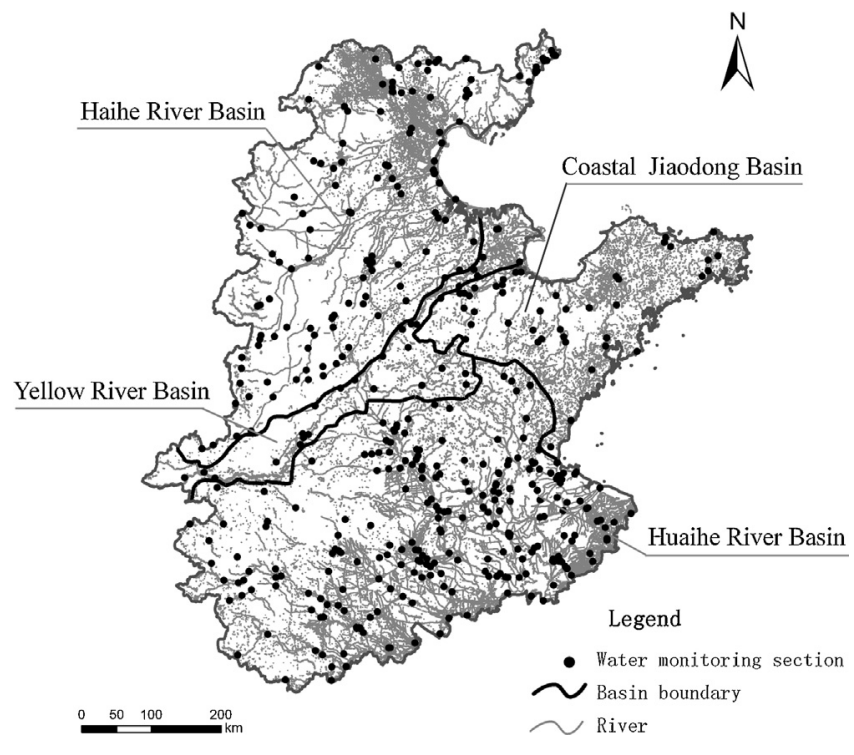

Fig. 3. Location of water monitoring sections in Huang-Huai-Hai Plain.

mainly include COD, TN, TP and $\mathrm{NH}_{3}-\mathrm{N}$ (Bhaduri et al., 2000; Ren et al., 2003). Based on existing research and the characteristics of Huang-Huai-Hai Plain, this paper selects water environmental quality indices as follows: $\mathrm{COD}, \mathrm{TN}, \mathrm{TP}, \mathrm{NH}_{3}-\mathrm{N}, \mathrm{DO}$ and $\mathrm{BOD}_{5}$. Then, water environmental quality assessment of the four river basins in Huang-Huai-Hai Plain (Fig. 3) is carried out according to the indices values of Class I-V in the environmental quality standards for surface water (GB 3838-2002) (SEPA, 2002).

Based on the land use transition analysis and water environmental quality assessment, spatial econometric regression models including Spatial Lag Model (SLM), Spatial Error Model (SEM) and ordinary least squares (OLS) are used to explain the correlationships between 15 categories of land use transitions and six kinds of water environmental quality indices of 187 monitoring sections in four river basins of Huang-Huai-Hai Plain. Specifically, the data of 15 categories of land use transitions during 2000-2010 and the changes of average value of six kinds of water environmental quality monitoring indices from 2000 to 2010 at the municipal level are used to conduct spatial regression analysis, to reveal the inner correlation between land use transitions and water environmental changes. Equations of the three spatial econometric regression models are explained as follows: 
SLM assumes that the value of the dependent variable $y$ in a site depends on the values of it in neighboring regions. It is thus a formulation of the idea of a spatial spillover. For example, the indicator values in one area will be affected by the surrounding areas. SLM is expressed as follows (Anselin, 1988):

$y=\rho W y+X \beta+\varepsilon$

where $y$ is the variation of water environmental quality index in each grid, $X$ contains a set of explanatory variables for the regression relationship with $\beta$ as the corresponding regression coefficient, $\rho$ is a spatial autoregressive coefficient indicating the extent to which variations in the observations $y$ are explained by the average of neighboring observation values, $\varepsilon$ is the model error terms and $W$ is spatial weight matrix.

Compared with SLM, the spatial dependence in the SEM enters through the errors rather than through the neighboring values of the dependent variable in the SLM (Anselin, 2002; Anselin et al., 1996).

SEM is specified as:

$y=X \beta+\varepsilon$ and $\varepsilon=\lambda W \varepsilon+\mu$

where $y, X, \beta, W$ are the same as them in Eq. (1), $\lambda$ is a spatial autoregressive coefficient, $\varepsilon$ is regression residuals, and $\mu$ is normally distributed random error.

Ordinary least squares (OLS) model explains the relationship between a dependent variable and a collection of independent variables. The value of dependent variable is defined as a linear combination of the independent variables plus an error term:

$y_{i}=\beta_{0}+\sum_{j=1}^{k} \beta_{j} x_{i j}+\varepsilon_{i}$

where $y_{i}$ is the dependent variable, $x_{i j}$ are the independent variables, $\beta_{0}$ is a constant term, $\beta_{j}$ are the regression coefficients, $\varepsilon_{i}$ is a normally distributed errors of prediction.

\section{Results}

\subsection{Land use transitions in Huang-Huai-Hai Plain}

In order to analyze the internal structural variability of LULC in the study area, spatial overlay analysis was carried out based on the two interpreted land use maps. A map of land use changes over the period from 2000 to 2010 was obtained (Fig. 4) and a change matrix of each compared LULC type in 2000 and 2010 was obtained (Table 1).

Land use had changed significantly over the whole period from 2000 to 2010 in Huang-Huai-Hai Plain, which was characterized by the decrease of farmland and the increase of construction land and water body. From the perspective of construction land change, the built-up area expanded very quickly, from 4,423,668 ha in 2000 to $6,430,442$ ha in 2010 , with an increase of $2,006,774$ ha, or $45.36 \%$, especially the expansions of Beijing, Tianjin, northwest of Anhui province and north of Jiangsu province were more significant (Fig. 2 and Table 1). On the contrary, the farmland decreased from $29,066,375$ ha in 2000 to $26,949,362$ ha in 2010 , with a decrease of $7.28 \%$ (Table 1 ). The distribution of increased construction land is coupled roughly with the decreased farmland (Fig. 2). Grassland and unused land decreased by $9.63 \%$ and $38.83 \%$, respectively. However, water body and forested land increased by $27.09 \%$ and $5.88 \%$, respectively, during the period from 2000 to 2010 (Table 1).

For exploring the internal conversion between different LULC types, which took place between the two compared periods of 2000 and 2010, we treated the change (decrease or increase) of a LULC type in 2010 relative to the compared year 2000 as a result of several "loss or gain" conversions (Long et al., 2007). The expansion of

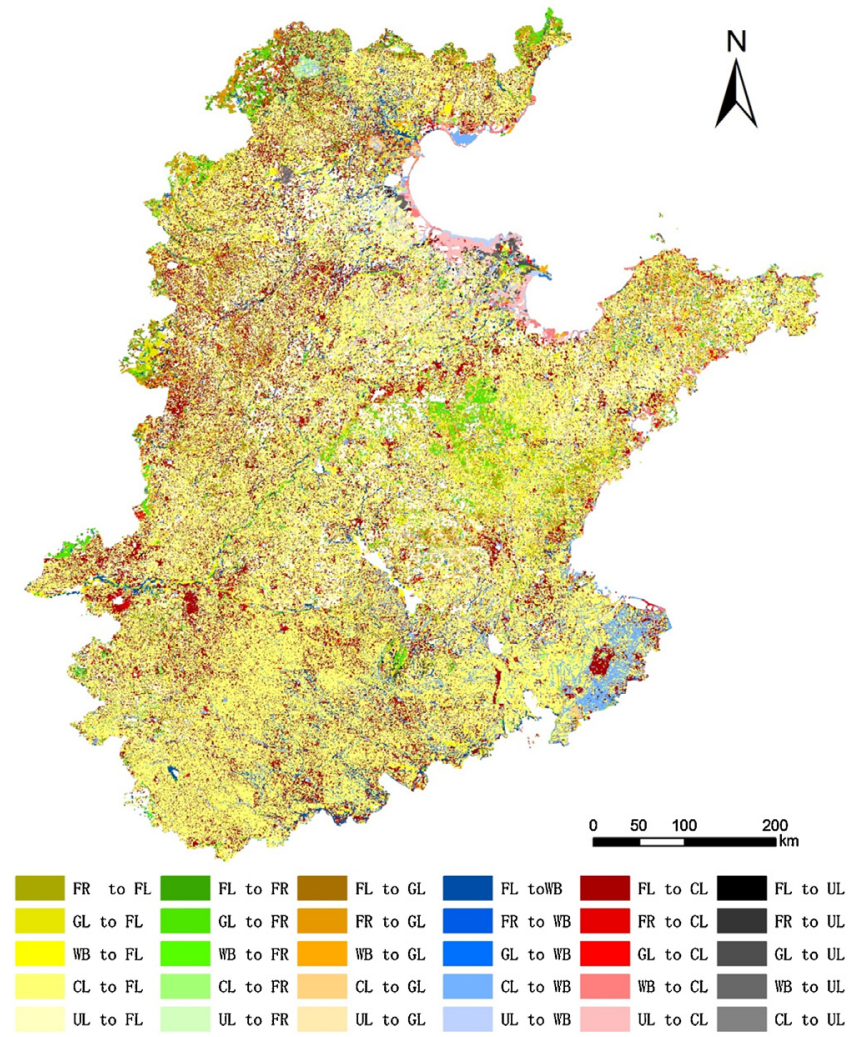

Fig. 4. Change pattern of land use in Huang-Huai-Hai Plain during 2000-2010. Note: FL, farmland; CL, construction land; FR, forested land; WB, water body; GL, grassland UL, unused land.

construction land was caused mainly by the decrease of farmland, grassland and unused land, accounting for $90.84 \%, 2.47 \%$ and $2.26 \%$, respectively (Table 2 ).

\subsection{Water environmental quality assessment}

Based on the data from the 187 monitoring sections in the four river basins of Huang-Huai-Hai Plain, a map of space distribution of the regional water environmental quality assessment in 2010 was obtained by using geostatistics and radial basis function interpolation method (Fig. 5). Clearly we can see that the water environmental quality of Haihe River Basin was the worst among the four river basins, while the best belonged to the Coastal

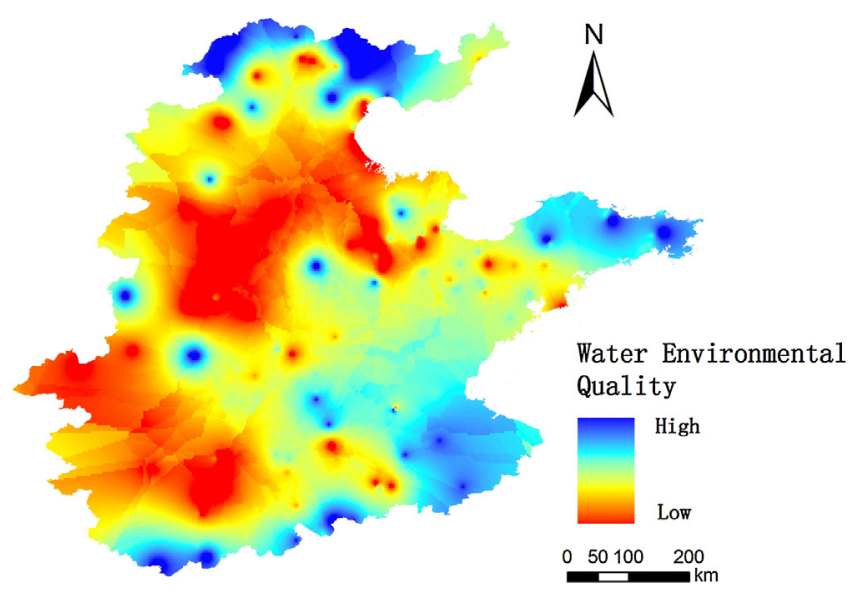

Fig. 5. Water environmental quality of Huang-Huai-Hai Plain in 2010. 
Table 1

Change matrix of each compared LULC type in 2000 and 2010 in Huang-Huai-Hai Plain (ha).

\begin{tabular}{|c|c|c|c|c|c|c|c|c|}
\hline \multirow[t]{2}{*}{ LULC type in 2000} & \multicolumn{7}{|c|}{ LULC type in 2010} & \multirow[t]{2}{*}{ Changes in 2010 (\%) } \\
\hline & FL & FR & GL & WB & $\mathrm{CL}$ & UL & Total & \\
\hline FL & $25,235,074$ & 320,182 & 155,761 & 502,219 & $2,806,220$ & 46,919 & $29,066,375$ & -7.28 \\
\hline FR & 222,594 & $1,542,866$ & 99,994 & 18,297 & 68,499 & 6538 & $1,958,788$ & 5.88 \\
\hline GL & 193,778 & 147,565 & $1,358,491$ & 33,527 & 76,311 & 57,686 & $1,867,359$ & -9.63 \\
\hline WB & 200,816 & 20,237 & 25,600 & 800,867 & 68,214 & 30,148 & $1,145,882$ & 27.09 \\
\hline $\mathrm{CL}$ & 927,849 & 36,499 & 31,946 & 77,544 & $3,341,342$ & 8487 & $4,423,668$ & 45.36 \\
\hline UL & 169,250 & 6592 & 15,783 & 23,804 & 69,856 & 63,729 & 349,013 & -38.83 \\
\hline Total & $26,949,362$ & $2,073,941$ & $1,687,575$ & $1,456,258$ & $6,430,442$ & 213,507 & $38,811,085$ & - \\
\hline
\end{tabular}

Note: FL, farmland; CL, construction land; FR, forested land; WB, water body; GL, grassland; UL, unused land.

Table 2

Internal conversions between LULC types from 2000 to 2010 and the percentages taken by corresponding types in such loss or gain conversions.

\begin{tabular}{|c|c|c|c|c|c|c|c|c|c|c|c|}
\hline LULC type & Loss or gain in $2010(\%)$ & Type (1) & Percent (\%) & Type (2) & Percent (\%) & Type (3) & Percent (\%) & Type (4) & Percent (\%) & Type (5) & Percent (\%) \\
\hline FL & -7.28 & $\mathrm{CL}$ & 73.24 & WB & 13.11 & FL & 8.36 & GL & 4.07 & UL & 1.22 \\
\hline FR & 5.88 & FL & 60.29 & GL & 27.79 & $\mathrm{CL}$ & 6.87 & WB & 3.81 & UL & 1.24 \\
\hline GL & -9.63 & $\mathrm{FL}$ & 38.08 & FL & 29.00 & $\mathrm{CL}$ & 15.00 & UL & 11.33 & WB & 6.59 \\
\hline WB & 27.09 & FL & 76.63 & $\mathrm{CL}$ & 11.83 & GL & 5.12 & UL & 3.63 & FL & 2.79 \\
\hline $\mathrm{CL}$ & 45.36 & FL & 90.84 & GL & 2.47 & $\mathrm{UL}$ & 2.26 & $\mathrm{FL}$ & 2.22 & WB & 2.21 \\
\hline UL & -38.83 & $\mathrm{FL}$ & 59.33 & $\mathrm{CL}$ & 24.49 & WB & 8.34 & GL & 5.53 & $\mathrm{FL}$ & 2.31 \\
\hline
\end{tabular}

Note: FL, farmland; CL, construction land; FR, forested land; WB, water body; GL, grassland; UL, unused land.

Jiaodong Basin. Specifically, the areas of water environmental quality belonging to Class V and below Class V were mainly distributed in the central of Hebei province, northwest of Shandong province, north of Henan and Anhui provinces, and south of Tianjin. Water with Class IV was mainly distributed in the mid-west coastal area of Shandong Peninsula and the northern part of Jiangsu province. The areas with Classes II and III of water environmental quality were mainly distributed in the north of Huang-Huai-Hai Plain, the east of coastal area of Shandong Peninsula. Water with Class I was mainly distributed in the two cities of and Zhangjiakou and Chengde of Hebei province.

The water of Haihe River Basin mainly belonged to Class V and below Class V in 2000. There were 35 and 4 water environmental quality monitoring sections, the water environmental quality of which belonged to Class $\mathrm{V}$ and below Class V, respectively, accounting for $53.85 \%$ and $6.15 \%$ of the monitoring sections in this basin, while the number decreased to 27 and 8 in 2010, accounting for $41.54 \%$ and $12.31 \%$ of 65 total sections in this basin, respectively. Although the sections with Class V water decreased 8, but that below Class $\mathrm{V}$ increased 4 during this period. In terms of major water pollutants of Haihe River, there are $\mathrm{DO}, \mathrm{COD}, \mathrm{BOD}_{5}$, $\mathrm{NH}_{3}-\mathrm{N}$, volatile phenol and oil, which were distributed in the North Canal flowing through Yulinzhuang section of Beijing and the Wangjiabai section of Langfang city of Hebei province, the Chahe River flowing through the Dongsongmen section of Cangzhou city of Hebei province and the Tianlongzhuang section of Dezhou City of Shandong province, and the Fuhe River flowing through the Anzhou and Jiaozhuang sections of Baoding city of Hebei province.
The water of Huaihe River Basin mainly belonged to Classes IV and V, and below Class V, and the corresponding water environmental quality monitoring sections were 25, 11 and 27 in 2000, accounting for $33.78 \%, 14.86 \%$ and $36.49 \%$ of 74 total sections in this basin, respectively; however, in 2010, the corresponding water environmental quality monitoring sections were changed to 15,9 and 30 , respectively. It is worth to mention that the sections with water below Class V increased 3, although the general water environment was improved to some extent during this period. The major water pollutants of Huaihe River Basin included DO, COD, $\mathrm{BOD}_{5}$ and $\mathrm{NH}_{3}-\mathrm{N}$, which were mainly distributed in the Huiji River and Wohe River in Bozhou city, the Heici River and Quanhe River in Fuyang city and the Kuihe River and Sui River in Suzhou city of Anhui province.

The water of Yellow River Basin mainly belonged to Classes III and IV in 2000, and the water environmental quality was gradually getting better. In 2010, water environmental quality of Yellow River Basin mainly belonged to Classes II and III instead. COD, $\mathrm{NH}_{3}-\mathrm{N}$, and oil were the main water pollutants in this basin. The water of Coastal Jiaodong Basin mainly belonged to Classes II-IV, and the corresponding water environmental quality monitoring sections were 3, 5 and 22 in 2000, respectively, but in 2010, which were changed to 5,8 and 23, respectively. The increase of sections with Classes II and III water showed that the water environment in this basin was improved obviously. The major water pollutants of Coastal Jiaodong Basin included COD, $\mathrm{BOD}_{5}$ and Oil. COD and $\mathrm{BOD}_{5}$ were mainly distributed in the Xiaoqinghe River and Zhangzenghe River flowing through Binzhou city and Weifang city of Shandong province. However, Oil was mainly distributed in the Xiaoqinghe

Table 3

Water quality statistics of monitoring sections in Huang-Huai-Hai Plain in 2000 and 2010.

\begin{tabular}{|c|c|c|c|c|c|c|c|c|}
\hline \multirow[t]{2}{*}{ Water quality index $(\mathrm{mg} / \mathrm{L})$} & \multicolumn{2}{|l|}{ Mean } & \multicolumn{2}{|l|}{ SD } & \multicolumn{2}{|l|}{ Min } & \multicolumn{2}{|l|}{ Max } \\
\hline & 2000 & 2010 & 2000 & 2010 & 2000 & 2010 & 2000 & 2010 \\
\hline DO & 5.8348 & 6.8561 & 2.6139 & 2.3749 & 0.1000 & 0.1000 & 11.7600 & 14.9200 \\
\hline $\mathrm{BOD}_{5}$ & 15.7779 & 7.4091 & 21.6699 & 8.1255 & 1.3600 & 0.7500 & 125.4600 & 65.7400 \\
\hline $\mathrm{NH}_{3}-\mathrm{N}$ & 6.1672 & 3.5369 & 10.8859 & 5.8162 & 0.0060 & 0.0300 & 63.2455 & 37.1000 \\
\hline COD & 83.9489 & 35.7828 & 96.9631 & 27.0169 & 7.5000 & 4.0800 & 413.9091 & 187.2000 \\
\hline TN & - & 7.2410 & - & 8.5090 & - & 0.4750 & - & 46.3800 \\
\hline $\mathrm{TP}$ & - & 0.4975 & - & 0.7796 & - & 0.0130 & - & 4.7990 \\
\hline
\end{tabular}

Note: The data of TN and TP in 2000 are lacked. 
River and Zhimaihe River flowing through Dongying city of Shandong province.

The statistical analysis of the water environmental quality in Huang-Huai-Hai Plain (Table 3), i.e., the maximum, minimum and mean value of the major water environmental quality indices showed that on the whole the water environment in the study area was obviously improved. For example, the maximum value of COD appeared in Huangzhuang monitoring section of Guangfu River, Jining city of Shandong province in 2000 was $132.44 \mathrm{mg} / \mathrm{L}$, which was 8.33 times of the limited standard value of Class V water. However, in 2010 the value reduced to $10.53 \mathrm{mg} / \mathrm{L}$, which was much better than that in 2000. The maximum value of $\mathrm{BOD}_{5}$ had been monitored in Dongjiazhuang section of Bailanghe River, Weifang city of Shandong province in 2000 was $125.46 \mathrm{mg} / \mathrm{L}$, which was about 12.5 times of the limited standard value of Class V water. Nevertheless, in 2010 the value reduced to $7.64 \mathrm{mg} / \mathrm{L}$, which was also much improved than that in 2000 . Of course, there was also certain index increased during this period, e.g., DO (Table 3).

\subsection{Correlationships between land use transitions and water environmental changes}

To some extent, the relationship between land use transitions and water environmental quality indices changes is stable. For example, if the correlationship between the transition from farmland to construction land and the change of water environmental quality index COD is positive, then we can conclude that during the same period there is a negative correlation between the transition from construction land to farmland and the change of COD. Therefore, we only need to consider 15 kinds of land use transitions in the process of spatial regression analysis. The results are shown in Table 4.

Based on the results of spatial regression analysis of the three models OLS, SLM and SEM, we can see that the fitting coefficients $\left(R^{2}\right)$ of SLM and SEM models are higher than that of OLS model, indicating the effectiveness of spatial regression interpretation of the former two is obviously higher than that of the latter one. So this paper mainly considers the regression analysis results of SLM and SEM models, from which the model results with higher $R^{2}$ value are chosen firstly. The spatial lag parameter $(W-Y)$ of SLM model and residual parameter (Lambda) of SEM model are of significant positive correlation with water environmental quality indices, indicating that the water environmental quality at municipal level is not only affected by the land use transitions of the city, but also affected by the land use transitions of adjacent cities, both of which influence the water environmental quality together. In general, the farmland was transformed into forested land and grassland, grassland and water body were transformed into construction land, and grassland was transformed into water body had significant correlation with most indices of water environmental quality in the study area. No significant correlation was observed between other land use transitions and water environmental quality indices. The land use transitions of Huang-Huai-Hai Plain were characterized as the decrease of farmland and the increase of construction land and water body. Table 2 shows that farmland and construction land accounted for $76.63 \%$ and $11.83 \%$ of the increase of water body, respectively. Therefore, this study focuses on the transitions from farmland to other land use types and from other land use types to construction land, and analyzes the correlation between abovementioned land use transitions and water environmental quality indices changes.

Correlation analysis between the transitions from farmland to other land use types and water environmental quality indices changes shows that: the transition from farmland to forested land has a significant negative correlation with the changes of $\mathrm{NH}_{3}-\mathrm{N}$, $\mathrm{BOD}_{5}$ and COD whose coefficients reached the significant level

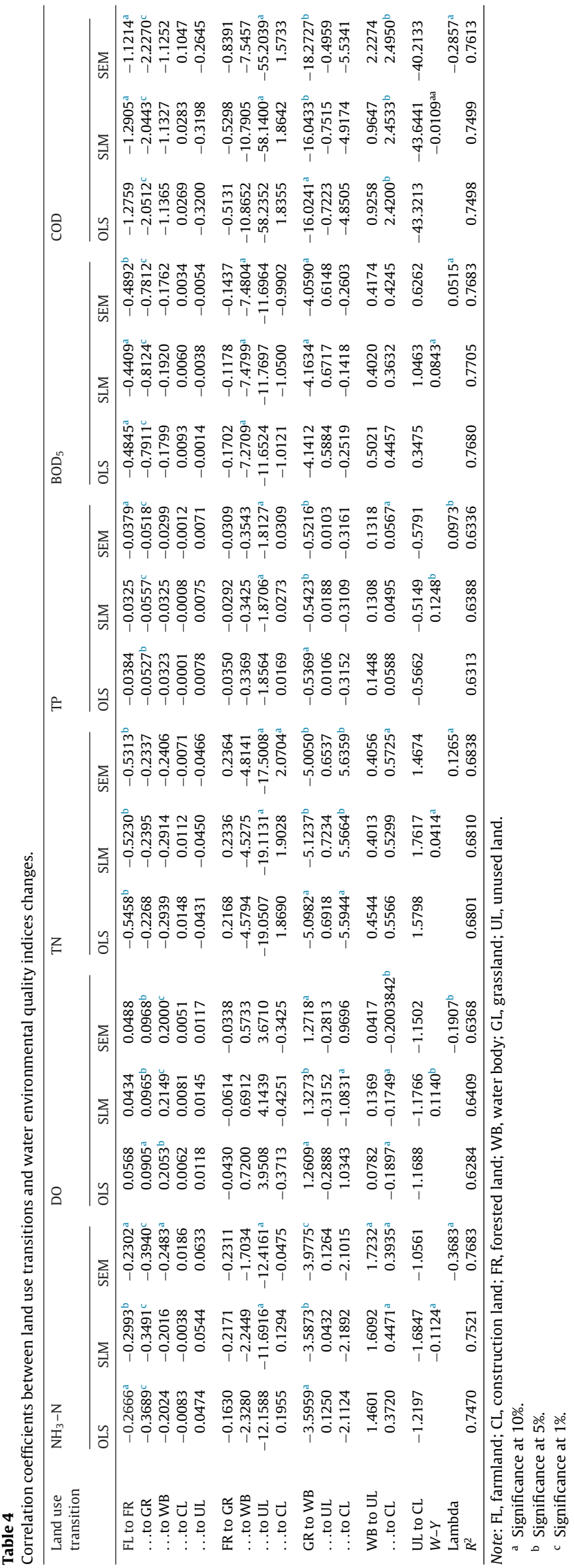


on statistics, especially with $\mathrm{TN}$ at the significant level of $5 \%$, indicating that the amount of $\mathrm{NH}_{3}-\mathrm{N}, \mathrm{BOD}_{5}, \mathrm{COD}$ and $\mathrm{TN}$ decreased as the farmland transformed into forested land (Table 4). The transition from farmland to grassland has also a significant negative correlation with the changes of $\mathrm{NH}_{3}-\mathrm{N}, \mathrm{TP}, \mathrm{BOD}_{5}$ and COD whose coefficients reached $1 \%$ significant level, indicating that the amount of $\mathrm{NH}_{3}-\mathrm{N}, \mathrm{TP}, \mathrm{BOD}_{5}$ and COD decreased as the farmland transformed into grassland, while DO increased in this kind of transition (Table 4). Besides, the transition from farmland to water body has a significant positive correlation with DO at the significant level of $1 \%$. Due to the transition from farmland to forested land, grassland and water body, there is no use of chemical fertilizers and pesticides. Along with the functions plants and grass have in reducing soil erosion and adsorption of pollutants can effectively reduce the pollutants runoff into the waters and then improve the water environmental quality. The increase of water body area can make dry land or rivers gradually restore the ecological function and improve their purification ability, which has positive effects on improving the water environmental quality. From the above analysis, we can conclude that the increases of grassland, forested land and water body have positive effects on water environmental quality while the increase of farmland has negative effects on the water environmental quality, which is also consistent with recently related research (Fiquepron et al., 2013; Leon-Munoz et al., 2013; Zhang et al., 2011; Zhao et al., 2012).

Correlation analysis between the transitions from other land use types to construction land and water environmental quality indices changes shows that: the transition from grassland to construction land has a significant positive correlation with TN at the significant level of 5\%, indicating that the amount of TN increased as the grassland transformed into construction land. The transition from water body to construction land has a significant positive correlation with COD at the significant level of $5 \%$, and with $\mathrm{NH}_{3}-\mathrm{N}$ and TN whose coefficients also reached $10 \%$ significant level, but significant negative correlation with $\mathrm{DO}$, indicating that the amount of $\mathrm{COD}, \mathrm{NH}_{3}-\mathrm{N}$ and $\mathrm{TN}$ increased as the water body transformed into construction land, while DO decreased as the water body transformed into construction land. Besides, the transition from forested land to construction land also has a significant positive correlation with TN at the significant level of 10\%. During 2000-2010, there was $90.84 \%$ of the increased construction land derived from the decrease of farmland (Table 2), but the correlation between the transition from farmland to construction land and water environmental quality indices changes is not significant (Table 4), which shows that construction land use and farmland use have almost equal negative effects on water environmental quality.

\section{Conclusions and discussion}

This paper firstly analyzes the land use transitions, and then assesses the water environmental quality changes of Huang-HuaiHai Plain. Finally, it discusses the correlations between land use transitions and water environmental quality indices changes by using spatial regression analysis method. The results indicated that, during the research period, land use patterns of Huang-Huai-Hai Plain changed significantly, which were characterized by the loss of large quantities of farmland and the increase of construction land and water body. According to the results of water environmental quality assessment, the water environmental quality of Haihe River basin was the worst among the four river basins of Huang-Huai-Hai Plain, while the Coastal Jiaodong Basin showed the best. On the whole, the water environment in the study area was obviously improved, but there also existed partial deterioration as evidenced by the increase of monitoring sections with water environmental quality below Class V during 2000-2010, three in
Huaihe River Basin and four in Haihe River Basin. In general, the increases of grassland, forested land and water body have positive effects on water environmental quality while farmland and construction land have negative effects on that. Interestingly, the correlation between the transition from farmland to construction land and water environmental quality indices changes is not significant, which shows that construction land use and farmland use have almost equal negative effects on water environmental quality. From the above analysis, we can infer that accompanied by rapid industrialization and urbanization, large quantities of farmland and other non-construction land have been transformed into construction land gradually, which further led to the changes of water environmental quality.

The farmland accounts for $67.63 \%$ of the total area of HuangHuai-Hai Plain, which can reflect the common important role of farmland in the socio-economic development of other developing countries in East Asia even other continents. Although the farmland showed a decreasing trend, it is still the major land use type in most developing countries. Therefore, the chemical fertilizer and pesticide washed away from farmland are still important factors affecting local water environmental quality in the future. So, strengthening the management of agricultural non-point source pollution is pivotal to improve local water environmental quality. In addition, along with the farmland was transformed into construction land, a large number of industrial and domestic sewage would be produced, which must be strictly controlled to satisfy discharge standards and to ensure water environmental quality and safety. Based on the above analysis, the authors put forward some implications for the formulation of sound decisions from the perspectives of land resource rational use and water resource protection, especially the farming practices to improve the water environmental quality of plain areas in China and other developing countries.

First of all, to encourage the farmers rationally use the chemical fertilizer and pesticide so as to realize the ecological farming practices and the sustainable land use. Different types of farming practices such as application of chemical fertilizer and pesticides, and straw processing may cause different influences on surface water environmental quality (De Girolamo and Lo Porto, 2012; Ouyang et al., 2004; Valle et al., 2014), so a sound use of fertilizers could substantially reduce the amount of nutrients flowing into surface waters, although the effects of such a policy on crop yield and farm income would be negative in some cases. Therefore, at the household level, we need to strengthen the basic education to improve farmers' ability to carry out ecological farming practices, at the same time, strengthen the agricultural technology and science popularization such as soil testing in order to control the use of pesticide and fertilizer application amount and develop ecological agriculture and organic agriculture. In addition, it is indispensable to apply the economic measures and policies to promote sustainable land use, by subsidizing the economic loss of farmers due to adopting abovementioned ecological farming practices.

Secondly, to strengthen the management of rural construction land is also an important way to mitigate the negative effects on water environmental quality. As for rural settlements and rural land for affiliated facilities, the land uses of breeding livestock and poultry and residential activities would also cause heavy non-point pollution if not treated properly (Casali et al., 2010; Seeboonruang, 2012), so the layout and construction of the disposal facilities for living garbage and livestock and poultry manure are of great importance in Huang-Huai-Hai Plain. The location of village garbage and sewage collection, storage and disposal places must be distributed properly in order to connect with the garbage and sewage treatment facilities of the town and the city. So domestic sewage can be treated unified, avoid dispersed discharging. As for those farmers who live scattered with complex terrain conditions should construct a decentralized treatment of sewage, sullage, and garbage by 
individual houses and establishments (Sheela et al., 2014). Besides, the location of livestock and poultry breeding must be distributed properly too, ensuring it is not located in or near the living places. To advocate the solid-liquid pollutants of livestock and poultry treated respectively, solid waste for the production of organic fertilizer, and liquid waste discharges after biochemical treatment.

Thirdly, to improve the water environmental quality by rationally compiling and implementing village and town land use planning as well as urban planning. It is necessary to compile special land use planning at village and town level to promote the better integration of water resources management with land use plan and river basin management plan (Fidelis and Roebeling, 2014; Qi and Altinakar, 2011). Since the increases of grassland and forested land have positive effects on water environmental quality (Table 4), more attentions need to be paid to the urban green space system. For a long time, green space planning has been a relatively loopholes in China's urban and land use planning. The green land is usually relocated on edges or fragmented belt, resulting in its isolation with original green land and limit its ecological functions such as improving water environmental quality (Long et al., 2014). So, the urban areas of Huang-Huai-Hai Plain need to plan to construct more urban green land such as suburban forest park, water source conservation forests, wide urban forest belt, large lawn and introducing farmland into the city, and so on.

China is experiencing a rapid and far-reaching urban and rural transition development (Liu et al., 2014b; Long et al., 2012; Tan et al., 2013), which is also being experienced by other developing countries to a great extent. In the future, with the acceleration of industrialization and urbanization, China and other developing countries will face an accelerated land use transitions and undergo a process of agricultural intensification, which will bring about foreseeable threatening for water environmental quality, and affect the regional ecological environment and economical sustainable development. As such, we should strengthen the study of land use transitions, especially on the changes of recessive land use morphology includes land use features in terms of aspects of quality, price, property rights, management mode, input and productive ability (Long, 2014a), and their relations with the groundwater and the biophysical basis that determines the land-use/water interactions (Garmendia et al., 2012; Ouyang et al., 2014), so can we use the land resource sustainably, and promote the coordinated economic, social and ecological development of the plain areas of China as well as other developing countries undergoing rapid urban-rural transformation development.

\section{Acknowledgments}

This work was supported by the National Natural Science Foundation of China (Grant Nos. 41171149 and 41130748 ), the National Key Technology R\&D Program of China (Grant No. 2014BAL01B05) and Non-profit Industry Financial Program of Ministry of Land and Resources of China (Grant No. 201511004-3).

\section{References}

Amiri, B.J., Nakane, K., 2009. Modeling the linkage between river water environmental quality and landscape metrics in the Chugoku District of Japan. Water Resour. Manag. 23 (5), 931-956.

Andersson, E., Brogaard, S., Olsson, L., 2011. The political ecology of land degradation. Annu. Rev. Environ. Resour. 36, 295-319.

Anselin, L., 1988. Spatial Econometrics: Methods and Models. Kluwer Academic Publisher, Dordrecht.

Anselin, L., 2002. Under the hood: issues in the specification and interpretation of spatial regression analysis. Agric. Econ. 27, 247-267.

Anselin, L., Bera, A., Florax, R., Yoon, M., 1996. Simple diagnostic tests for spatial dependence. Reg. Sci. Urban Econ. 26, 77-104.

Basnyat, P., Teeter, L.D., Flynn, K.M., Lockaby, B.G., 1999. Relationships between landscape characteristics and non-point source pollution inputs to coastal estuaries. Environ. Manag. 23 (4), 539-549.
Bhaduri, B., Harbor, J., Engel, B., 2000. Assessing watershed-scale long-term hydrologic impacts of land-use change using a GIS-NPS model. Environ. Manag. 26 (6), 643-658.

Cai, Y.L., 2011. Understanding environmental change planning sustainable development: development directions for geography in China. Bull. Chin. Acad. Sci. 26 (4), 390-398 (in Chinese).

Cai, Y.L., 2013. On geography in contemporary scientific and social perspectives. Chin. J. Nat. 35 (1), 30-39 (in Chinese).

Casali, J., Gimenez, R., Diez, J., Alvarez-Mozos, J., 2010. Sediment production and water environmental quality of watersheds with contrasting land use in Navarre (Spain). Agric. Water Manag. 97 (10), 1683-1694.

Chen, L.D., Fu, B.J., Xu, J.Y., Gong, J., 2003. Location-weighted landscape contrast index: a scale independent approach for landscape pattern evaluation based on "Source-Sink" ecological processes. Acta Ecol. Sin. 23 (11), 2406-2413 (in Chinese).

Chen, R.S., Ye, C., Cai, Y.L., Xing, X.S., Chen, Q., 2014. Rural out-migration and landuse transition in China: past, present and trend. Land Use Policy 40, 101-110.

De Girolamo, A.M., Lo Porto, A., 2012. Land use scenario development as a tool for watershed management within the Rio Mannu Basin. Land Use Policy 29 (3), 691-701.

Duncan, R., 2014. Regulating agricultural land use to manage water environmenta quality: the challenges for science and policy in enforcing limits on non-point source pollution in New Zealand. Land Use Policy 41, 378-387.

Fidelis, T., Roebeling, P., 2014. Water resources and land use planning systems in Portugal-exploring better synergies through Ria de Aveiro. Land Use Policy 39, 84-95.

Fiquepron, J., Garcia, S., Stenger, A., 2013. Land use impact on water environmenta quality: valuing forest services in terms of the water supply sector. J. Environ. Manag. 126, 113-121.

Fu, B.J., Zhao, W.W., Chen, L.D., Liu, Z.F., Lu, Y.H., 2005. Eco-hydrological effects of landscape pattern change. Landsc. Ecol. Eng. 1 (1), 25-32.

Gao, C., Zhu, J.Y., Dou, Y.J., Zhang, T.L., 2004. Landscape management practices for the control of non-point source pollution: methods and principals. Acta Ecol. Sin. 24 (1), 109-116 (in Chinese).

Garmendia, E., Mariel, P., Tamayo, I., Aizpuru, I., Zabaleta, A., 2012. Assessing the effect of alternative land uses in the provision of water resources: evidence and policy implications from southern Europe. Land Use Policy 29, 761-770.

Jia, L., Wang, W.Y., Li, Y.H., Yang, L.S., 2010. Heavy metals in soil and crops of an intensively farmed area: a case study in Yucheng city, Shandong province, China. Int. J. Environ. Res. Public Health 7 (2), 395-412.

Johnson, L.B., Richards, C., Host, G.E., Arthur, J.W., 1997. Landscape influences on water chemistry in midwestern stream ecosystems. Freshw. Biol. 37 (1), 193-208.

King, R.S., Baker, M.E., Whigham, D.F., 2005. Spatial considerations for linking watershed land cover to ecological indicators in streams. Ecol. Appl. 15 (1), 137-153.

Kong, X.B., Lai, R., Li, B.G., 2014. Fertilizer intensification and its impacts in China's HHH plains. Adv. Agron. 125, 135-169.

Lambin, E.F., Meyfroidt, P., 2010. Land use transitions: socio-ecological feedback versus socio-economic change. Land Use Policy 27 (2), 108-118.

Leon-Munoz, J., Echeverria, C., Marce, R., Riss, W., Sherman, B., Iriarte, J.L., 2013. The combined impact of land use change and aquaculture on sediment and water environmental quality in oligotrophic Lake Rupanco. J. Environ. Manag. 128, 283-291.

Li, X.B., 2008. Theoretical hypotheses about agricultural land use changes and the relevant propositions about environmental impacts. Adv. Earth Sci. 23 (11), 1124-1129 (in Chinese).

Li, X.B., 2009. Research priorities for land use in the accelerated phase of urbanization. China Popul. Resour. Environ. 19 (5), 1-5 (in Chinese).

Li, X.B., Hao, H.G., Ran, S.H., Zhu, H.Y., Tian, Y.J., 2010a. Management transition of the ecological building in China and its demand for science and technology innovations. Acta Ecol. Sin. 30 (12), 3340-3345 (in Chinese).

Li, Y.R., Liu, Y.S., Long, H.L., 2012. Characteristics and mechanism of village transformation development in typical regions of Huang-Huai-Hai plain. Acta Geogr. Sin. 67 (6), 771-782 (in Chinese).

Li, Y.R., Liu, Y.S., Long, H.L., Guo, Y.J., 2013. Village transformation development resources and environment effects and their optimal regulation in the suburb of metropolitan: the case of Beicun in Shunyi District, Beijing. Acta Geogr. Sin. 68 (6), 825-838 (in Chinese).

Li, Y.R., Long, H.L., Liu, Y.S., 2010b. Industrial development and land use/cover change and their effects on local environment: a case study of Changshu in eastern coastal China. Front. Environ. Sci. Eng. China 4 (4), 438-448.

Liu, J.Y., Kuang, W.H., Zhang, Z.X., Xu, X.L., Qin, Y.W., Ning, J., Zhou, W.C., Zhang S.W., Li, R.D., Yan, C.Z., Wu, S.X., Shi, X.Z., Jiang, N., Yu, D.S., Pan, X.Z., Chi, W.F., 2014c. Spatiotemporal characteristics, patterns, and causes of land-use changes in China since the late 1980s. J. Geogr. Sci. 24 (2), 195-210.

Liu, Y., Huang, X.J., Yang, H., Zhong, T.Y., 2014a. Environmental effects of landuse/cover change caused by urbanization and policies in Southwest China Karst area: a case study of Guiyang. Habitat Int. 44, 339-348.

Liu, Y.S., Fang, F., Li, Y.H., 2014b. Key issues of land use in China and implications for policy making. Land Use Policy 40, 6-12.

Liu, Y.S., Wang, J.Y., Long, H.L., 2010. Analysis of arable land loss and its impact on rural sustainability in Southern Jiangsu Province of China. J. Environ. Manag. 91 (3), 646-653.

Long, H.L., 2014a. Land consolidation: an indispensable way of spatial restructuring in rural China. J. Geogr. Sci. 24 (2), 211-225.

Long, H.L., 2014b. Land use policy in China: introduction. Land Use Policy 40, 1-5. 
Long, H.L., Li, Y.R., Liu, Y.S., Woods, M., Zou, J., 2012. Accelerated restructuring in rural China fueled by 'increasing vs. decreasing balance' land-use policy for dealing with hollowed villages. Land Use Policy 29, 11-22.

Long, H.L., Liu, Y.Q., Hou, X.G., Li, T.T., Li, Y.R., 2014. Effects of land use transitions due to rapid urbanization on ecosystem services: implications for urban planning in the new developing area of China. Habitat Int. 44, 536-544.

Long, H.L., Liu, Y.S., Wu, X.Q., Dong, G.H., 2009. Spatio-temporal dynamic patterns of farmland and rural settlements in Su-Xi-Chang region: implications for building a new countryside in coastal China. Land Use Policy 26 (2), 322-333.

Long, H.L., Tang, G.P., Li, X.B., Heilig, G.K., 2007. Socio-economic driving forces of land-use change in Kunshan, the Yangtze River delta economic area of China. J. Environ. Manag. 83, 351-364.

Mehaffey, M.H., Nash, M.S., Wade, T.Q., 2005. Linking land cover and water environmental quality in New York city's supply watersheds. Environ. Monit. Assess. 107, 29-44.

Mou, B., Wang, Q.C., Hershey, A.E., Yu, H.L., Guo, B.Q., 2004. Land-use, tream order and stream water physical and chemical qualities. Acta Ecol. Sin. 24 (7), 1486-1492 (in Chinese).

National Bureau of Statistics of China (NBSC), 2012. China Statistical Yearbook. China Statistics Press, Beijing.

Ouyang, J.L., Song, C.M., Yu, Z.R., Zhang, F.R., 2004. The farm household's choice of land use type and its effectiveness on land quality and environment in HuangHuai-Hai Plain. J. Nat. Resour. 19 (1), 1-11 (in Chinese).

Ouyang, Y., Zhang, J.E., Cui, L.H., 2014. Estimating impacts of land use on groundwater environmental quality using trilinear analysis. Environ. Monit. Assess. 186 (9), 5353-5362.

Qi, H.H., Altinakar, M.S., 2011. A conceptual framework of agricultural land use planning with BMP for integrated watershed management. J. Environ. Manag. 92 (1), 149-155.

Qiu, J., 2010. China faces up to groundwater crisis. Nature 466, 308.

Ren, W., Zhong, Y., Meligrana, J., 2003. Urbanization, land use, and water environmental quality in Shanghai: 1947-1996. Environ. Int. 29 (5), 649-659.

Robinson, G.M., Carson, D.A., 2013. Applying landscape science to natural resource management. Ecol. Soc. 18 (1), 32, http://dx.doi.org/10.5751/ES-05639-180132

Seeboonruang, U., 2012. A statistical assessment of the impact of land uses on surface water environmental quality indexes. J. Environ. Manag. 101, 134-142.

Sheela, A.M., Letha, J., Swarnalatha, K., Baiju, K.V., Sankar, D., 2014. Urgency for sustainable development in coastal urban areas with reference to weather pattern, land use, and water environmental quality. Environ. Monit. Assess. 186 (5), 3221-3237.
Short, A.G., 2013. Governing change: land-use change and the prevention of nonpoint source pollution in the North Coastal Basin of California. Environ. Manag. 51 (1), 108-125.

State Environmental Protection Administration (SEPA), 2002. Environmental Quality Standards for Surface Water (GB 3838-2002).

Tan, M.H., Robinson, G.M., Li, X.B., 2011. Urban spatial development and land use in Beijing: implications from London's experiences. J. Geogr. Sci. 21, 49-64.

Tan, M.H., Robinson, G.M., Li, X.B., Xin, L.J., 2013. Spatial and temporal variability of farm size in China in context of rapid urbanization. Chin. Geogr. Sci. 23 (5), 607-619.

Turner, I.I., Lambin, B.L., Reenberg, E.F.A., 2007. The emergence of land change science for global environmental change and sustainability. Proc. Natl. Acad. Sci. U. S. A. 104 (52), 20666-20671.

Uuemaa, E., Roosaare, J., Mander, U., 2007. Landscape metrics as indicators of river water environmental quality at catchment scale. Nord. Hydrol. 38 (2), 125-138.

Valle, R.F., Varandas, S.G.P., Fernandes, L.F.S., Pacheco, F.A.L., 2014. Environmental land use conflicts: a threat to soil conservation. Land Use Policy 41 $172-185$.

Versace, V.L., Ierodiaconou, D.F., 2008. Regional scale models for relating land cover to basin surface water environmental quality using remotely sensed data in a GIS. Environ. Monit. Assess. 142 (2), 171-184.

Yu, C.Q., Gong, P., Yin, Y.Y., 2011. China's water crisis needs more than words. Nature $470,307$.

Zampella, R.A., Procopio, N.A., Lathrop, R.G., 2007. Relationship of land use/land cover patterns and surface-water environmental quality in the Mullica river basin. J. Am. Water Resour. Assoc. 43 (3), 594-694.

Zhang, S.H., Liu, Y., Wang, T.W., 2014. How land use change contributes to reducing soil erosion in the Jialing River Basin, China. Agric. Water Manag. 133, 65-73.

Zhang, X.L., Kong, X.B., 2014. The sustainable utilization of cultivated land resources in Huang-Huai-Hai Plain under groundwater crisis. China Land Sci. 28 (5), 90-96 (in Chinese)

Zhang, Y.J., Chen, S., Xiang, J.C., 2011. Correlation between the water environmental quality and land use composition in the river side area: a case of Chaohu Lake Basin in China. Resour. Environ. Yangtze Basin 20 (9), 1054-1060 (in Chinese).

Zhao, P., Xia, B.C., Qin, J.Q., Zhao, H.R., 2012. Multivariate correlation analysis between landscape pattern and water environmental quality. Acta Ecol. Sin. 32 (8), 2331-2341 (in Chinese). 